\title{
Thinking the Transformative
}

\author{
Steffen Bösenberg
}

Editorial Summary: Steffen Bösenberg's contribution »Thinking the Transformative r reflects the dynamic momentum of reflexive design and research. In reference to the working process of his doctoral thesis, he highlights the procedural circularity of reflexive, concept-driven research approaches, tracing the »circular motion of constant reflection and rethinking «. Hereby a transdisciplinary concept of "plasticity is explored as a productive tool in the analysis of design methods in adaptive reuse. Decision-making, reconsideration, comparison or evaluation thereby become considerable as reciprocally interlinked processes, which equally depend upon and shape each other. Most interestingly, the transformation and plasticity of the process mirrors the dynamic dimension of the investigated case studies. [Katharina Voigt]

Keywords: Adaptive Reuse; Transformation; Plasticity; Design Methodology; Reflexive Design; Post-Industrial Design; Concepts.

\section{The Circular Motions of the Reflexive}

Reflexive research as a discursive topic of recent decades is an intentionally iterative mode of approaching the world as a not entirely rationalizable complex. From a position of acknowledging the entanglement of the implicit and the explicit, it hereby tries to gain access to a body of knowledge otherwise hidden within the individual practices of design. This entanglement is particularly noticeable in the field of architecture, where it is both inherently tasked with shaping multiple layers of our physical reality, and - as a scientific practice - finds itself in a position where field-specific modes of research are still being explored. Here, as a circular motion of constant reflection and rethinking and open to a multi-methodical research design, reflexiveness provides insightful notions on the contexture of the "vagueness and clarity « within the swerving process of creativity (Buchert 2014: 20-25). The reflexive is hereby more than a retrospective reflection; rather, it entails a prospectively directed mode of thinking that not only excavates 
knowledge from within the creative, but strives for creative research output as well.

In the often chaotic, or at least ambiguous, process of designing, reflexiveness serves as an evaluating force. For »reflective practitioners «, an insight that can be evaluated against underlying or superimposed theoretical concepts is directed not only at the development of their own individual creative acting, but also renders practically gained knowledge accessible to others (Schön 1983; Visser 2010). The reflexive, as a sociological mode of thinking as it appears toward the end of the 2oth century, subsequently introduces a layer of explicitly self-conscious reflection, critical to one's own position or field (e.g. Bourdieu/Wacquant 1992). Within these notions, reflexivity in research asks both for prospective as well as retrospective motions in the research design, which consequently gains a more developmental, dynamic, and ultimately self-transformative momentum (Attia/ Edge 2017). Potentially, this retains the malleability of the research that opens it up to different methodical approaches of research and positions adjacent to architecture's established practical tools, such as drawings and diagrams. In connecting modes of designing with modes of research, especially with an output of specific design methods in mind, it seems insightful not only to reflect on theoretical concepts on the practice, but also to explore the tools of practice for the theoretical (Buchert 2014: 8-14). Within these circular motions, the research project underlying this short exploration of the reflexive seeks to intertwine both concepts from outside the field as well as tools from within the practice.

As discussed further in the context of the author's own research, where the choice of methods can be a developmental process, the question arises of if, and how, an overlaying conceptual framework can stabilize these multi-directional motions of the research to coherently synthesize the obtained insights as transferable knowledge.

\section{Plasticity as Reflexive Concept in Research on Adaptive Reuse}

Strategies of adaptive reuse that reintroduce industrial structures as spatial resources play a vital role in current and future developments of our urban habitat (Hassler/Kohler 2004: 6-9; Eisinger 2013). Gaining conceptual access to evaluation and transformation of these seemingly alienated typologies is an architectural task that has yet to be framed explicitly as a design-methodical topic. In the context of the described circular motions of reflexivity, 
the author's research project »Plasticity. Strategy of post-industrial transformation " iteratively attempts to frame specific notions within a theoretical research background and best-practice case studies, reflecting an overlaying concept of »plasticity« in order to generate design-methodical knowledge.

Hereby, conceptualizing the transformative as a way of organizing knowledge is critical, as adaptive reuse is neither a mere contemporary nor isolated phenomenon but complexly interwoven with multiple discourses and practices. Countless examples of anonymous architecture, such as the many famous conversions of ancient theaters, showcase specific spatial and iterative design strategies that rely on the morphology of the structures and their entanglement within an urban context, rendering the spatial as a resource (Jäger-Klein 2013). However, as examples mainly outside a theoretical reflection, their qualities and underlying strategies tend to be implicit.

Explicit concepts of the adaptive, on the other hand, have been explored in architectural theory with varying degrees of depth. As a topic of preservation and methodology, adaptability emerges during the 19th century in the work of architects and thinkers such as Viollet-Le-Duc or John Ruskin (Scott 2007: 44-61). As a notion of sustainable usage of resources, it surfaces as a partially explicit, partially implicit topic within the discourses on »obsolescence as they surface in the early 20 th century in the New World metropolises of New York and Chicago (Abramson 2017: 14-20). To some extent, the two discourses both intertwine and divert; the mid-century preservationist movements argue retrospectively for a conservation of the old, while discourses of obsolescence seek prospectively for new forms of adaptability in the buildings of the future (Cairns/Jacobs 2017: 119-124). Subsequently, strategies in between the two emerge - with Rowe and Koetter's Collage City, modern takes on the ruin such as in the work of Arata Isozaki, or Aldo Rossi's notion of "permanence« (Rowe 1978; Isozaki 1968; Rossi 1984: 57-61). As an explicit method of designing, it is reflected upon more precisely toward the end of the 2oth century, as seen in the works of Hermann Czech or Vittorio Gregotti (Czech 1989; Gregotti 1991). In contemporary architecture, such explicitly transformative strategies have become distinct features in the positions of numerous high-profile practices like EM2N, Lacaton \& Vassal or the recent critical theoretical and practical reflections on preservation by Rem Koolhaas (Carver et al. 2014). As such, the topic of transformation, in its multivalent forms scattered across its long but mostly unreflected practical continuity and diverse theoretical understanding, is challenging to frame. Where there is neither typological nor programmatic commonality, the 
research project thus seeks to frame a commonality in their design strategies. It hereby turns to a term that has its own history as a possible tool for rethinking transformation - plasticity.

Plasticity - at its core - focuses on the act of transformation, instead of its mere products, hence becoming a potential way to look at specific strategies within adaptive reuse as well. Other fields have already argued a comparable potential - as recently explored in the work of philosopher Catherine Malabou (e.g. Malabou 1996; 2009), but most instructively in neurobiology. Within the latter, after a lively and critical discourse in the 1970s, it continues to be a driving force in neuroscientific research. (Buchtel 1978; Berlucchi/ Buchtel 2009). But even though architecture seems so closely related to the term and the morphogenetic qualities it describes, plasticity lacks a comparably distinct and complex definition within the field. Its ability to link temporal factors to morphological systems might therefore be illuminating when explored.

Within the research design, this conceptualization follows up on the theoretical baseline of the project. In a hermeneutic-phenomenological tradition, the research background of conversion and the specifics on the reuse of industrial typologies is hereby approached as an exegetical, historical research that is reflected upon specific lines of thought regarding transformation within architecture. This broad framing serves as a first lens in analyzing and reducing the relatively heterogenous context of adaptive reuse.

A transdisciplinary reading of the term "plasticity« further acts as a tool of structuring found aspects. In phenomenological terms, the notion of plasticity is consequently explored as a way of sharpening intention as a directedness of thought. In a reflexive manner, it is not seen as a fixed framework but is constantly evaluated and reshaped throughout the research.

A case study on best-practice-built projects such as the Toni Areal in Zurich or the Fondazione Prada in Milan then tries to iteratively refine this framework by applying it as an analytic device. To evaluate the found aspects, a diagrammatical analysis explores a more explicit understanding of the concrete spatial dependencies, merging the transdisciplinary approach with a more commonly elaborated architectural medium. The diagram hereby serves as an explicitly reflexive and thus knowledge-generating tool, as it has been explored in the past few decades by several theorists and practitioners (Frichot 2011). In a final step, the outlined architectural approach to 
"plasticity « is revisited to extract and exemplify specific aspects as a transferable design method. It is thus seen as a malleable tool in itself.

\section{Transformative Research on Transformative Strategies}

The notion of reflexiveness - as presented in this research - is utilized to make sense of an underlying, partly implicit understanding of the practice within the transformation of the built environment, which, in this case, entails the obsolete industrial structures of a post-industrial society.

As shown, adaptive reuse hereby presents itself as a widely researched and, as a development of the last few decades, extensively publicized topic (e.g. Petzet/Heilmeyer 2012; Baum/Christiaanse 2012, et al.). Yet in terms of understanding the underlying notions of the transformative from the perspective of the designing architect, knowledge is scattered, sometimes hidden, within a field that spans from preservationist discourses over technical guidelines to philosophical endeavors on the fixity of architecture itself, and across a wide range of individual architectural projects.

Approaching an idea within this field requires not only a focus that can be laid upon the body of knowledge within creativity and built like a magnifying glass to extract one isolated set of aspects. Rather, it requires an additional tool that can grasp at and then extract the widely branched aspects of an idea and provide the means of disentanglement accordingly.

In the case of the presented research, the concept of plasticity as a specific notion of the transformative has serendipitously already been explored in multiple discourses across scientific fields. This equips it with some level of agency but more importantly with an established framework of rules and critiques (Paillard 1976).

It hereby generates two circular motions within the research: First, an inner reflexive motion that sharpens the strategies understood through the notion of plasticity by finding, extracting, and analyzing topics of architectural theory and practice. Second, the iterative evaluation of the alignment against the exterior conceptions of plasticity to question their transferability to the architectural field. It also addresses the condition of architecture as an »open work«, as could be argued in reflection of Umberto Eco's writings on the openness of art (Eco/Robey 1962) - not a fixed monument but a continuous flux of intermediate states. The inherent challenge of the concept of authorship is thereby, and arguably, also a reason for the long-term 
invisibility of adaptive reuse in avant-gardist and high-profile positions in the field (Scott 2007: 1-19).

Conveying a self-aware perspective of the field and the subsequent reflection of its own context, the research project additionally attempts to impart a reflexive view on architecture's basic notions of flexibility, adaptability, transformability and whether they might be complimented by distinctive definitions of plasticity as a template for thinking transformatively in a more general fashion. This veering motion between the content of the research background and its underlying intentions seems to enforce a reflexive stance in order to thoroughly make sense of the subject.

The research design is ultimately tasked with inquiring about the existence of commonalities in architectural transformation - despite the inherently different tasks within industrial adaptive reuse which span across distinct typologies, individual programmatic challenges, and their respective unique contexts (Hassler/Kohler 2004: 59-66). What does the transformation of a late-1970s dairy plant in Zurich by EM2N have in common with Diller Scorfidio + Renfro's reconfiguration of the 1930s New York High Line or O.M.A.'s partly additive, partly intertwining reconfiguration of the Fondazione Prada in Milan? Here, distinct strategies of contexture and transformation create a comparability, and therefore transferability, where without a reflexive approach, an overarching understanding of the transformative may be difficult to develop. At its core lies a specific way of thinking the transformative, not merely the adaptive. As such, it also looks past the adaptation of the object reflecting its impact on its context.

While this presented research introduces a tool of framing the transformative from outside the profession, architecture itself also provides its distinctive tools of analysis and synthesis. Plasticity - as a complex idea of how matter, form and function intertwine - here finds a possibly surprising similarity in its motives concerning the method of the diagram. This notion is especially relevant as it has been explored in connection to Gilles Deleuze and Félix Guattari's ideas on the diagrammatic throughout the late 2oth century. This discourse was transposed into the realm of architecture by several practitioners and theorists such as Stan Allen, Ben van Berkel or Caroline Bos (e.g. van Berkel/Bos 1998).

Among other aspects, they posed the question of whether a focus on matter and its generative potential - instead of just »imposing « form onto matter - accesses a new thinking about the nature of the built (DeLanda 1998). Although the diagrammatical discourse of the late 1990s and early 
2000s stood in the light of the novelty of computational parametric design, and the notion of matter has not been understood as industrial bricks and mortar but as parameters, forces, and rules, this notion seems relatively close to the presented ideas on transformation. The conceptual similarities to the intended overcoming of "form « in favor of exploring the forces underlying »transformation « are notable. As a generative force, the diagram in this sense appears to be a suitable tool to steer the conceptual framework of plasticity closer to the actual process of designing architectural transformation. The complementary disposal of such different concepts and tools requires a constant adaptation in which different aspects are evaluated against each other without dismantling the overall structure. It is here where the circular motion of the research design itself helps to react to these interchanges.

\section{Malleable Frameworks}

In the complexity of the built - the partial implicitness of the act of designing and the wide range of notions connected to the topic of adaptive reuse - a research method is needed that does not only frame a section of, but sifts through, a broad field of notions. In this research, the aim is to turn to other fields and try to transfer their supposed means of conceptualization, and incorporate them - specifically the concept of plasticity - within a reflexive design strategy aimed at an outcome directed at designing practitioners. A reflexive approach, that is able to react - but also constantly needs to be investigated - to the multi-layered body of knowledge it approaches, be it theoretical positions, built objects, or underlying concepts, can offer an insightful research framework through its own malleability. It helps in diluting a framework that is ultimately not superimposed as an external concept of plasticity but implemented as a reactive interplay between conceptions within a transdisciplinary reading of the term.

Herein lies the ambition to explain the found phenomena of transformation in their complexity, meaning to grasp architecture as a multifaceted realm in which the virtual ideas of designing and the physical reality of the built intertwine in manifold ways. The transformative, after all, does not manifest itself in isolated aspects but as a combination of different qualities and intentions, such as form, material, program and structure, among many others.

In addition, the connectiveness of a reflexive design that can be linked to its circular motion that provides a constant force of evaluation makes it a 
viable instrument for exploring the arsenal of both architectural and scientific tools. It, of course, remains to be seen and evaluated how transferable the aforementioned strategies will be; it should be noted, that the represented notions of reflexivity pose their difficulties in exactly this heterogenous, sometimes ambivalent and constantly veering movement. The conceptualization of a term from outside the profession, as presented here, can therefore also be seen as an attempt to steer this process, not only as a conceptual framework.

Plasticity is thus a proposal for a tool beyond architecture's usual means and attempts to add a more conceptual and strategic instrument that, within a reflexive approach, provides both a pro- and retrospective force. It potentially gives access to a rich field of expertise hidden in individual positions and the built products of architectural practice, possibly creating a transferable output for others to build upon, where it would otherwise remain in the realm of the unique. Thus, it can hopefully serve as a starting point for further research on transformative design methods, as well as their application in practice, which extend further than just the obsolete industrial.

References

Abramson, Daniel M. (2017): Obsolescence. An Architectural History, Chicago:

University of Chicago Press.

Attia, Mariam/Edge, Julian (2017):

»Be(Com)Ing a Reflexive Researcher: A

Developmental Approach to Research

Methodology «, in: Open Review of

Educational Research 4(1), 33-45.

Baum, Martina/Christiaanse, Kees (2012): City as Loft. Adaptive Reuse as a Resource for Sustainable Urban Development, Zurich: gta Verlag.

Berkel, Ben van/Bos, Caroline eds. (1998): »Diagram Work«, in: Anyone Corporation, Any Magazine, no. 23 (June).
Berlucchi, G./Buchtel, H. A. (2009). »Neuronal Plasticity: Historical Roots and Evolution of Meaning «, in: Experimental Brain Research 192(3), 307-319.

Bourdieu, Pierre/Wacquant, Loïc [1992]: Réponses: pour une anthropologie réflexive, Paris, Seuil. - English translation: An Invitation to Reflexive Sociology, Chicago: Chicago University Press, 1992.

Buchert, Margitta (2014): Reflexive Design Design and Research in Architecture, Berlin: Jovis Berlin.

Buchtel, H. A (1978): »On Defining Neural Plasticity«, in: Archives /taliennes de Biologie 116 (3-4), 241-247. 
Cairns, Stephen/Jacobs, Jane M. (2017): Buildings Must Die: A Perverse View of Architecture, Cambridge: MIT Press.

Carver, Jordan/Koolhaas, Rem/OteroPailos, Jorge/Wigley, Mark (2014): Preservation Is Overtaking Us, New York: Columbia University Press.

Czech, Hermann (1989). »Der Umbau«, in: Umbau. Theorien Zum Bauen Im Bestand, UMBAU 29 Basel: Birkhäuser, 10-13.

DeLanda, Manuel (1998): »Deleuze, Diagrams, And the Genesis of Form«, in: ANY Diagram Work. Data Mechanics for a Topological Age (23), 30-34.

Eco, Umberto/Robey, David (1989 [1962]). The Open Work, Cambridge: Harvard University Press.

Eisinger, Angelus (2013): »The Social Value of Transformation «, in: Baum, Martina/ Christiaanse, Kees: City as Loft. Adaptive Reuse as a Resource for Sustainable Urban Development, Zürich: gta Verlag, 67-71.

Frichot, H. (2011): »Drawing, Thinking, Doing: From Diagram Work to the Superfold «, in: ACCESS. Critical Perspectives on Communication, Cultural and Policy Studies 30 (1), 1-10.

Gregotti, Vittorio (1991): »Von Der Modifikation (Della Modificazione) «, in: Umbau. Theorien Zum Bauen Im Bestand, UMBAU 29, Basel: Birkhäuser, 10-13.

Hassler, Uta/Kohler, Niklaus (2004): Über das Verschwinden der Bauten des Industriezeitalters: Lebenszyklen industrieller Baubestände und Methoden transdisziplinärer Forschung, Tübingen: Wasmuth \& Zohlen.

Isozaki, Arata (1968): Re-Ruined Hiroshima. Ink and gouache with cut-and-pasted gelatin silver print on gelatin silver print, Museum of Modern Art, New York.

Jäger-Klein, Caroline. 2013. »Conversions in Urban History«, in: Baum, Martina/ Christiaanse, Kees, City as Loft. Adaptive Reuse as a Resource for Sustainable Urban Development, Zürich: gta Verlag, 59-66.
Malabou, Catherine (1996): L'Avenir de Hegel. Plasticite, Temporalite, Dialectique, Paris: VRIN.

Malabou, Catherine (2009): Plasticity at the Dusk of Writing: Dialectic, Destruction, Deconstruction, New York: Columbia University Press.

Paillard, Jacques (1976): »Réflexions sur l'usage de concept de plasticité en neurobiologie«, in: Journal de Psychologie Normale et Pathologique, no. $\mathrm{n}^{\circ} 1,15$.

Petzet, Muck/Heilmeyer, Florian (2012): Reduce, Reuse, Recycle, Ostfildern: Hatje Cantz Verlag.

Rossi, Aldo (1984 [1966]): The Architecture of the City, London: MIT Press.

Rowe, Colin (1978): Collage City, Reprint, Cambridge: MIT Press.

Schön, Donald (2003[1983]): The Reflective Practitioner. How Professionals Think in Action, 3rd edition, London: Ashgate.

Scott, Fred (2007): On Altering Architecture, London/New York: Routledge.

Visser, Willemien (2010): „Schön: Design as a Reflective Practice«, in: Collection, Parsons Paris School of art and design. Art, Design \& Psychology, 21-25. 


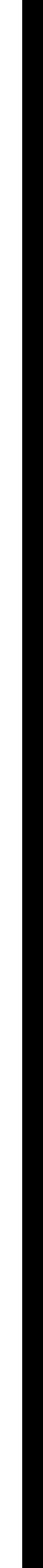

